\title{
Isolated DC/DC Converter Based Voltage Measuring System for Series Connected Supercapacitor Cells
}

\author{
Ugis Sirmelis $^{1,2}$, Linards Grigans ${ }^{1}$, Kaspars Kroics ${ }^{1,2}$ \\ ${ }^{1}$ Laboratory of Power Electronics \\ Institute of Physical Energetics \\ Riga, Latvia \\ Ugis.Sirmelis@gmail.com, Linards.Grigans@gmail.com, \\ Kaspars.Kroics@gmail.com
}

\author{
Janis Zakis ${ }^{2}$ \\ ${ }^{2}$ Institute of Industrial Electronics and Electrical \\ Engineering \\ Riga Technical University \\ Riga, Latvia \\ janis.zakis@ieee.org
}

\begin{abstract}
In this paper authors present a novel voltage measuring system that allows to measure the voltage of each cell for series connected supercapacitors (SCs). Proposed system is based on isolated DC/DC converter with multiple outputs that have equal voltages, which serve as reference voltage for each series connected supercapacitor. Two operation modes of the system are analyzed. Functionality of the system is verified with its prototype, which allows to measure voltage for series connected 8 SCs.
\end{abstract}

Keywords-voltage measurement; supercapacitors; Li-ion batteries;

\section{INTRODUCTION}

As supercapacitors become more and more commercialized, their application in recent years has become widespread. Due to relatively high power capability and extremely high cycle life, SCs are very often viewed as energy storage technology that can be used to recover braking energy in public electric transport systems or as power source in alternative energy systems[1],[2],[3]. However, mentioned SCs applications require connection of many SC cells in series, because SCs are low voltage devices with typical maximum cell voltage in the range between $2.7-2.85 \mathrm{~V}$ for commercially available supercapacitors. Since SCs parameters, even for one SCs type of the same manufacturer, have variance in rated capacitance and leakage resistance, problem of cell voltage imbalance arises. If SC bank with different voltages on SC cells is being charged, each cell voltage must be measured, to prevent SCs from being overcharged, which shortens SCs life [4],[5],[6]. Another problem that is caused by $\mathrm{SC}$ voltage imbalance is reduction of useful SC bank energy capacity [6],[7], [8],[9].

The basic method that allows measuring voltage of each battery cell is use of resistive divider. The more cells are connected in series, the more inaccurate results this method gives. Besides, very high precision resistors must be used for the cells that are in the upper part of the stack. Voltage measuring methods like: electromechanical relay matrix, voltage transfer with transistors or op-amps, individual isolation amplifiers, are analyzed in [10], [11],[12]. The main disadvantages of these methods are complexity and unreliability.
To equalize cell voltages in series connected energy storage elements (supercapacitor, electrochemical accumulators), different balancing circuits are used. All methods that allow cell voltage equalization can be divided in two groups - passive balancing and active balancing. Passive balancing via resistors dissipates excess charge from the cells with highest voltage and it is usually carried out during battery charging. Active balancing means that energy from the cells with higher voltage is transferred to the cells with lover voltages. This usually is done by the use of capacitors, transformers, inductors or DC/DC converters. Advantages and disadvantages of these methods are discussed in [6], [13],[14].

In literature and in practice a very common approach to treat voltage imbalance in Li-ion battery packs is a combination of voltage monitoring and passive balancing. For cells with higher energy capacities often one microcontroller is used for each cell. Microcontroller measures the voltage and temperature, controls shunting resistor and communicates with central controller, which collects data from all cells. Besides microcontroller is powered from the cell it monitors [15],[16]. For smaller batteries, e.g., batteries for electric bikes and scooters, one microchip that monitors and balances all battery cells is used. Such microchips usually allow monitoring from 4 to 12 cells and are powered from whole battery pack. These measuring systems are well suited for lithium based batteries, since normal operation voltage of these cells is in a range $2.5-$ $4.2 \mathrm{~V}$, which is sufficient to power monitoring circuits. However, this voltage range is not sufficient to use these systems for voltage monitoring of SC banks.

In this paper authors propose a novel voltage measuring system, which allows to measure individual cell voltages for series connected energy storage elements. Due to its wide voltage measuring range, proposed measuring system is particularly suitable for supercapacitor stacks. Functionality of voltage monitoring system is verified with prototype that allows measuring voltage for 8 series connected supercapacitors. Proposed voltage monitoring system can be used in combination of any cell balancing method. 


\section{Single ENDED ForWARD CONVERTER BASED Voltage MONITOR}

\section{A. Operation Principle}

As can be seen in Fig. 1, proposed voltage measuring system is based on single-ended isolated forward converter, which has many transformers with common primary winding and equal number of turns in secondary windings. The particular converter topology is chosen due to its simple control, however, other topologies can also be considered.

Control and measurement unit (CMU) sets reference voltage $\left(v_{r e f}\right)$ and controls duty cycle $d$ for transistors VT1 and VT2 to match filter capacitor voltages $\left(v_{C l}-v_{C n}\right)$ to reference voltage. Each filter capacitor voltage is compared to SC cell voltage with the use of comparators $\left(\mathrm{CMP}_{1}-\mathrm{CMP}_{\mathrm{n}}\right)$. If the voltage across any filter capacitor is higher than the voltage of matching $\mathrm{SC}$ cell $\left(\mathrm{SC}_{1}-\mathrm{SC}_{\mathrm{n}}\right)$, the corresponding comparator sets its output to "1", which means that particular SC cell voltage is lower than the reference voltage. Comparators output signal is filtered, to prevent oscillations, and then sent to $\mathrm{CMU}$ via isolated communication, which is not considered in this paper.

To ensure that filter capacitor voltages matches the reference voltage level, which is set in CMU, voltage feedback circuit from the first filter capacitor is introduced. Feedback voltage $\left(V_{f b}\right)$ in CMU is compared to $v_{r e f}$ and with the use of proportional-integral controller duty $d$ cycle is controlled.

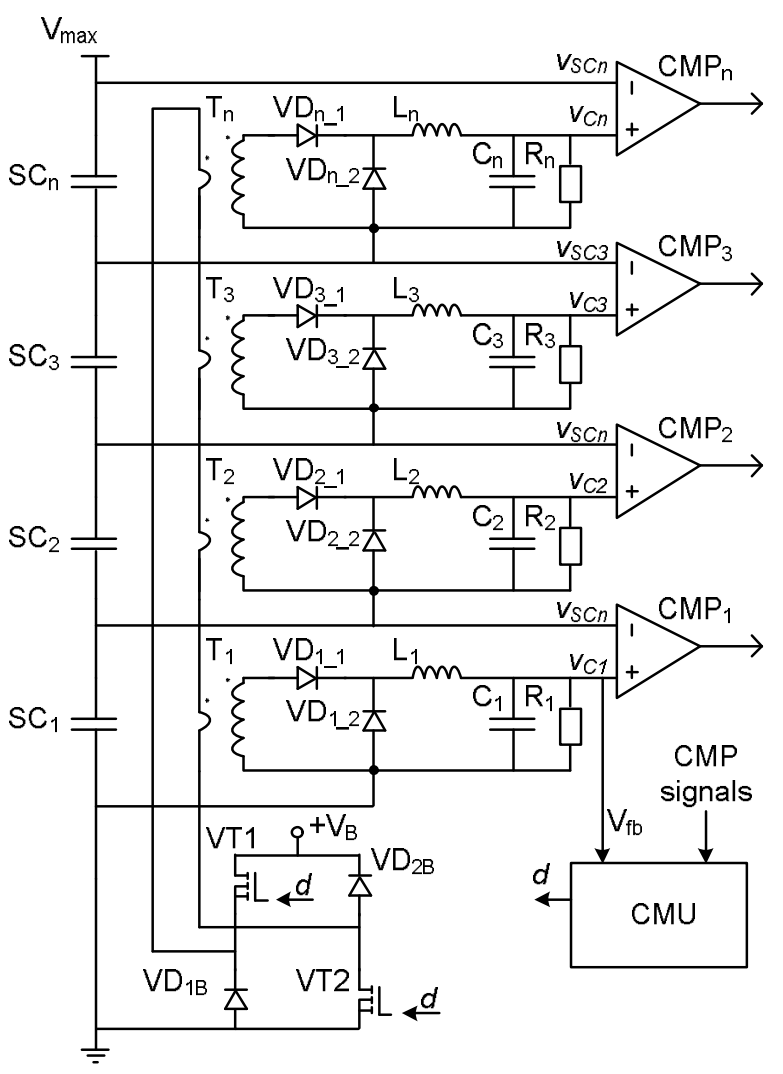

Fig. 1. Series connected SCs cells voltage measuring system.
As each measuring channel is not powered directly from a cell it monitors, proposed circuit allows measuring cell voltage starting from $0 \mathrm{~V}$. However it should be mentioned, that this also increases the cost of the system, since comparators must be powered from external isolated converter.

\section{B. Operation modes}

1) Continuous scan mode: In this mode proposed voltage monitoring system provides continuous information about voltage of all SC bank cells. The operation diagrams of this mode is depicted in Fig. 2, where it assumed that during one sampling period $\left(T_{\text {sample }}\right)$ voltage across SCs changes negligibly.

As can be seen in Fig. 2 reference voltage $v_{\text {ref }}$ is ramped in a range between $V_{\text {ref min }}-V_{\text {ref } \max }$. When $v_{\text {ref }}$ reaches the voltage value of some $\mathrm{SC}\left(v_{S C l}-v_{S C n}\right)$, corresponding comparator sets its output to " 1 ". Monitoring system control and measurement unit CMU detects changes in comparators output and assigns these events for voltage value, that is measured on capacitor $\mathrm{C}_{1}$.

Start new sampling cycle requires discharge of capacitors $\left(\mathrm{C}_{1}-\mathrm{C}_{\mathrm{n}}\right)$ with resistors $\left(\mathrm{R}_{1}-\mathrm{R}_{\mathrm{n}}\right)$ to voltage level equal to $V_{\text {ref min }}$. The time needed to discharge capacitors from $V_{\text {ref_max }}$ to $\bar{V}_{\text {ref min }}$ can be calculated as:

$$
t_{\text {disch }}=R \cdot C \cdot \ln \left(\frac{V_{\text {ref_max }}}{V_{\text {ref_min }}}\right),
$$

where : $R$-resistance $\mathrm{R}_{1}-\mathrm{R}_{\mathrm{n}}$

$C$ - capacitance of $\mathrm{C}_{1}-\mathrm{C}_{\mathrm{n}}$.

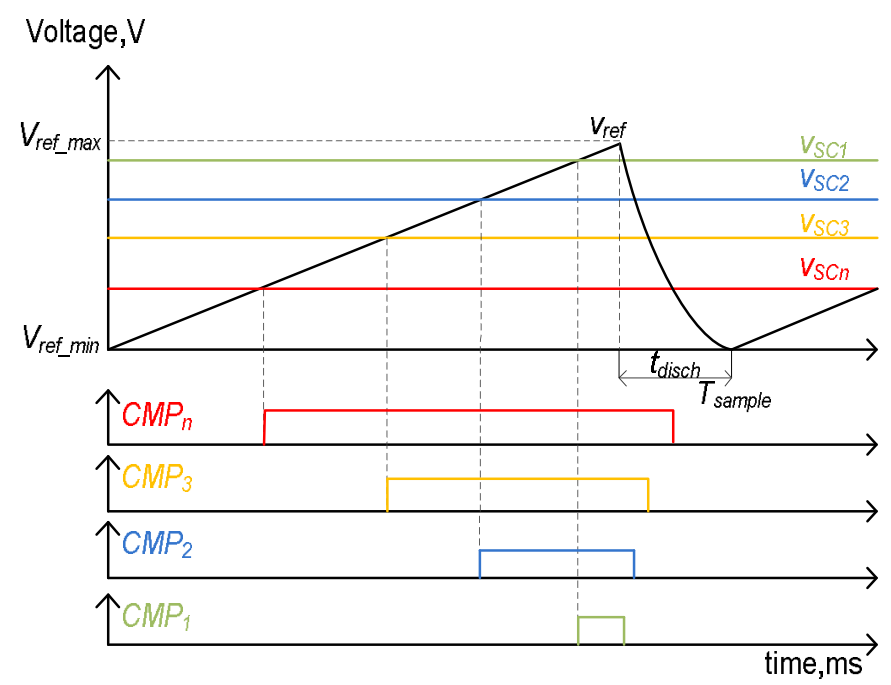

Fig. 2. Continuous scan mode operation diagrams.

2) Max/min voltage mode: The main function of $\min / \mathrm{max}$ operation mode is to prevent any supercapacitor cell in supercapacitor bank from being charged over maximum permissible voltage or discharged under preset minimum voltage level. 


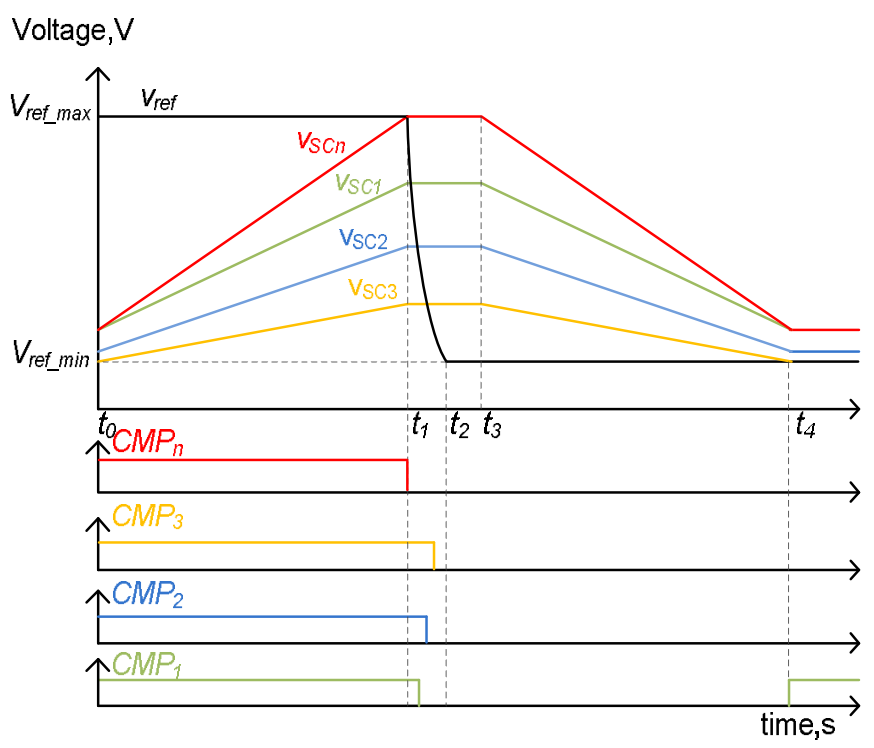

Fig. 3. Min/max mode operation diagrams.

The functionality of this operation mode can be seen in Fig. 3, where monitoring system diagrams are shown for the case when SCs with different capacitances and initial voltages are charged and discharged. From $t_{0}$ to $t_{l}$, when SCs charging takes place, all comparators outputs have value " 1 ", because none of SCs have reached maximum permissible voltage $V_{\text {ref_max }}$. At the time moment $t_{l}$ supercapacitor $\mathrm{SC}_{\mathrm{n}}$ voltage exceeds $V_{\text {ref } \max }$ value and the output of corresponding comparator $\overline{\mathrm{CMP}}_{\mathrm{n}}$ is set to " 0 ", which means that charging must be terminated. Between $t_{1}-t_{2} v_{\text {ref }}$ value is set to $V_{\text {ref_min }}$ and during this period all comparators set their outputs to " 0 ". If $v_{\text {ref }}$ value from $V_{\text {ref_max }}$ to $V_{\text {ref_min }}$ is decreased in a controlled manner, the voltage of each $\mathrm{SC}$ cell can be measured. At the time moment $t_{4}$ comparator $\mathrm{CMP}_{1}$ sets its output to " 1 ", thus indicating that $\mathrm{SCs}$ discharge must be stopped because $\mathrm{SC}_{1}$ has reached minimum voltage value.

\section{PRACTICAL IMPLEMENTATION}

To investigate the functionality of proposed voltage measuring system, its prototype was created and tested in the setup, which is partly shown in Fig. 4. Designed prototype enables voltage measuring for series connected 8 SC cells, however only 6 channels were connected to SC battery. Prototype doesn't include primary part of forward converters (isolated hybrid bridge) which is controlled from feedback circuit. In this setup reference voltage was set via external hybrid bridge that runs with constant duty cycle and $100 \mathrm{kHz}$ frequency, set by external signal generator.

Prototype board is designed to measure $8 \mathrm{SC}$ cells due to economical considerations - low cost isolated DC/DC converters with multiple outputs $(+15 /-15 \mathrm{~V})$, needed for powering comparators, are available on market. Each such DC/DC converter allows feeding of 2 comparator modules, which contain 4 comparators.

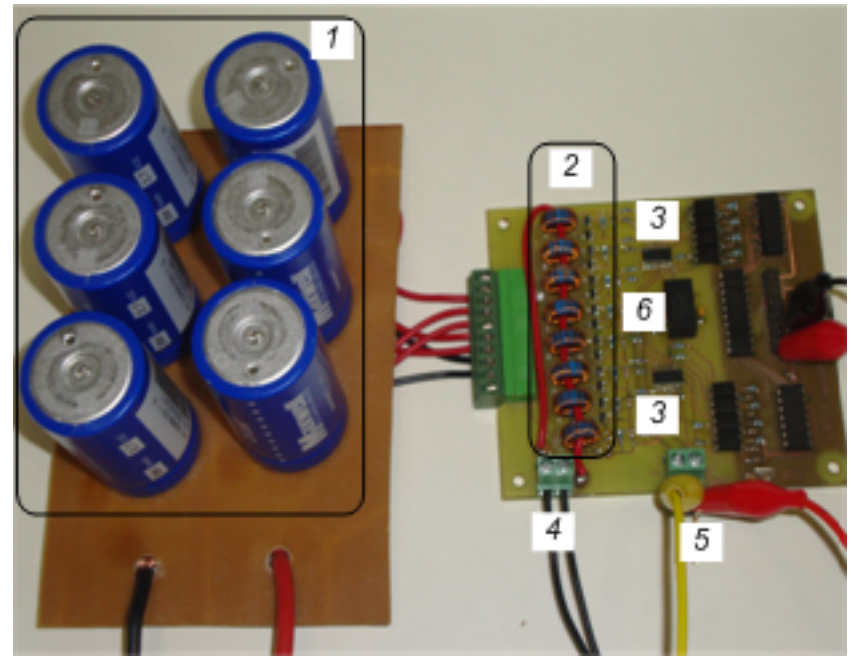

Fig. 4. Setup for test voltage measuring system (1. SCs bank; 2. transformers and voltage filters; 3. comparators; 4. Input from isolated hybrid bridge;5. Supply voltage to isolated DC/DC converter; 6. Isolated +/- $15 \mathrm{~V} \mathrm{DC/DC}$ converter for powering comparators).

Two experiments were carried out using this setup. The first experiment allowed estimation of proposed measuring system precision, while the second demonstrated the functionality of the system in $\mathrm{min} / \mathrm{max}$ operation mode.

Fig. 5 shows the results of an experiment where via external signal generator duty cycle was set to a value which forms $2 \mathrm{~V}$ voltage on filter capacitors. Measured filter capacitor voltage dispersion between all channels fitted in $0.02 \mathrm{~V}$ range. This dispersion arises due to the uneven parameters of electronic components (resistors, diodes, capacitors, inductors), however, such measurement precision can be considered as acceptable to use this system for voltage measurement for supercapacitors.

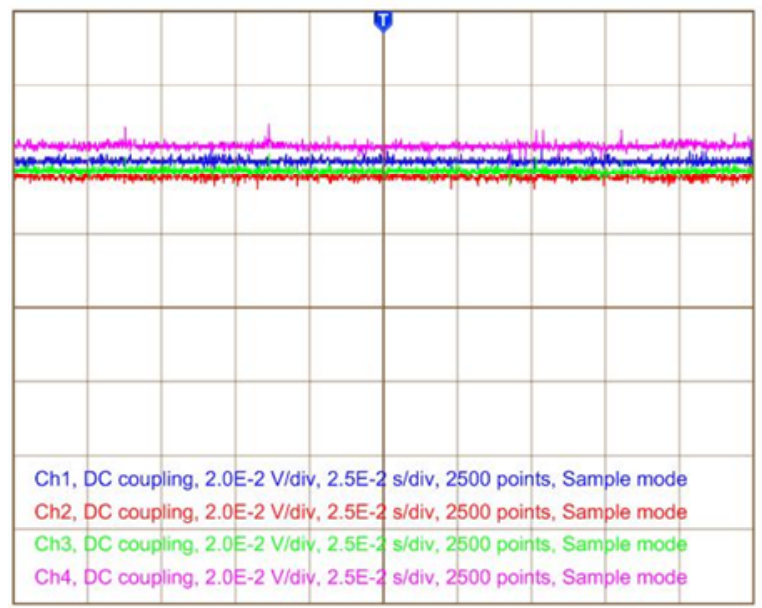

Fig. 5. Reference voltage measured on filter capacitors (CH1 and $\mathrm{CH} 2-$ voltages on filter capacitors with two lowest potentials, $\mathrm{CH} 3$ and $\mathrm{CH} 4-$ voltages on filter capacitors with two highest potentials).

Fig. 6 illustrates the results of a test where $\min / \max$ operation mode was tested. 4 signals were measured: $\mathrm{CMP}_{6}$ comparator, which monitors $\mathrm{SC}$ with highest potential, vc1- 
reference voltage measured on filter capacitor with lowest potential, vsc6 and vsc1- voltages of SCs with the highest and lowest potential, respectively. SCs had various initial voltages and were charged with $25 \mathrm{~A}$ current. When $\mathrm{SC}_{6}$ voltage reaches $2.5 \mathrm{~V}$ value, which matches the reference voltage, corresponding comparator $\mathrm{CMP}_{6}$ changes its output state from high to low, which demonstrates correct functionality of proposed measuring system.

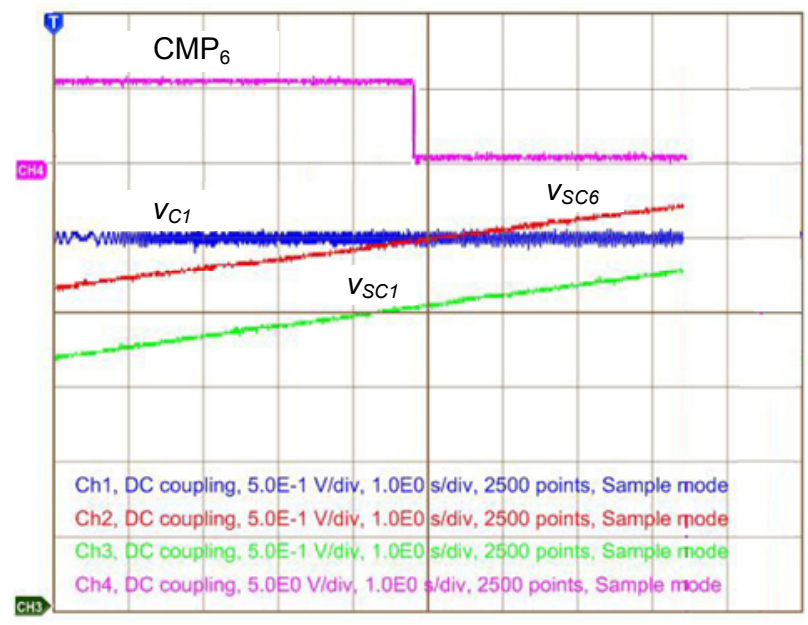

Fig. 6. Voltage monitoring system operation in Min/max mode.

\section{CONCLUSIONS}

Proposed voltage measuring system allows to solve so called "battery-stack problem" and can be used for voltage measurement for series connected SC cells in a very wide voltage range.

Since proposed circuit requires isolated hybrid bridge converter, it is more suitable for SC banks with high number of series connected SCs, as it allows to split additional costs between measuring channels.

Although electronic components, used in measuring system construction, have variation in parameters, they cause negligible effect on system accuracy.

For more efficient use of SC bank, proposed measuring system should be combined with some passive cell balancing method.

\section{ACKNOWLEDGMENT}

This research work has been supported by Latvian Council of Science (Project Nr. 673/2014).

\section{REFERENCES}

[1] L. Latkovskis, U. Sirmelis, and L. Grigans, "On-board supercapacitor energy storage: Sizing considerations,” Latv. J. Phys. Tech. Sci., vol. 49, no. 2, pp. 24-33, 2012.

[2] A. Rufer, D. Hotellier, and P. Barrade, "A supercapacitor-based energy storage substation for voltage compensation in weak transportation networks," IEEE Trans. Power Deliv., vol. 19, no. 2, pp. 629-636, Apr. 2004.

[3] J. Zakis, D. Vinnikov, O. Husev, and I. Rankis, "Dynamic behaviour of qZS-based bi-directional DC/DC converter in supercapacitor charging mode," in 2012 International Symposium on Power Electronics, Electrical Drives, Automation and Motion (SPEEDAM), 2012, pp. 764768.

[4] P. Kreczanik, P. Venet, A. Hijazi, and G. Clerc, "Study of Supercapacitor Aging and Lifetime Estimation According to Voltage, Temperature, and RMS Current," IEEE Trans. Ind. Electron., vol. 61, no. 9, pp. 4895-4902, Sep. 2014.

[5] R. Chaari, O. Briat, J. Y. Delétage, E. Woirgard, and J.-M. Vinassa, "How supercapacitors reach end of life criteria during calendar life and power cycling tests," Microelectron. Reliab., vol. 51, no. 9-11, pp. 1976-1979, Sep. 2011.

[6] D. Linzen, S. Buller, E. Karden, and R. W. De Doncker, "Analysis and evaluation of charge-balancing circuits on performance, reliability, and lifetime of supercapacitor systems," IEEE Trans. Ind. Appl., vol. 41, no. 5, pp. 1135-1141, Sep. 2005.

[7] L. Latkovskis, U. Sirmelis, L. Grigans, J. Cemovs, and K. Kroics, "Capacitance and leakage current balancing for supercapacitive energy storage system," Latv. J. Phys. Tech. Sci., vol. 49, no. 6 I, pp. 3-12, 2012 .

[8] R. Kötz, J.-C. Sauter, P. Ruch, P. Dietrich, F. N. Büchi, P. A. Magne, and P. Varenne, "Voltage balancing: Long-term experience with the $250 \mathrm{~V}$ supercapacitor module of the hybrid fuel cell vehicle HYLIGHT," J. Power Sources, vol. 174, no. 1, pp. 264-271, Nov. 2007.

[9] M. Okamura, K. Hayashi, and Y. Katoh, "Electronics to Boost the Usable Energy of Capacitors," in The 15th International Seminar on Double Layer Capacitors and Similar Energy Storage Devices, FL, USA, 2005.

[10] D. B. Garrett and T. . Stuart, "Transfer circuit for measuring individual battery voltages in series packs," IEEE Trans. Aerosp. Electron. Syst., vol. 36, no. 3, pp. 933-940, Jul. 2000.

[11] A. Hande, S. Kamalasadan, and A. Srivastava, "A Selective Voltage Measurement System for Series Connected Battery Packs," in Proceedings of the IEEE SoutheastCon, 2006, 2006, pp. 22-27.

[12] X. Wang and T. Stuart, "An Op Amp transfer circuit to measure voltages in battery strings," J. Power Sources, vol. 109, no. 2, pp. 253261, Jul. 2002.

[13] S. Lambert, V. Pickert, J. Holden, W. Li, and X. He, "Overview of supercapacitor voltage equalisation circuits for an electric vehicle charging application," in 2010 IEEE Vehicle Power and Propulsion Conference (VPPC), 2010, pp. 1-7.

[14] M. Daowd, N. Omar, P. Van Den Bossche, and J. Van Mierlo, "Passive and active battery balancing comparison based on MATLAB simulation," in 2011 IEEE Vehicle Power and Propulsion Conference (VPPC), 2011, pp. 1-7.

[15] K. Vitols, "Design of an embedded battery management system with passive balancing," in Education and Research Conference (EDERC), 2014 6th European Embedded Design in, 2014, pp. 142-146.

[16] D. Andrea, Battery Management Systems for Large Lithium Ion Battery Packs. Artech House, 2010. 